УДК 338.462

$10.17213 / 2075-2067-2020-5-209-223$

\title{
ГОСУДАРСТВО КАК КЛЮЧЕВОЙ СТЕЙКХОЛДЕР В РАМКАХ ПЕРСПЕКТИВ РЕАЛИЗАЦИИ ПРОЕКТОВ СС(U)S В РОССИИ ${ }^{1}$
}

\author{
(C) 2020 г. Н. В. Ромашева, А. А. Ильинова, О. О. Евсеева
}

\section{Санкт-Петербургский горный университет, г. Санкт-Петербург, Россия}

Проблема сокращения выбросов углекислого газа $\left(\mathrm{CO}_{2}\right)$ является сегодня широко обсуждаемой во всем мире. В последние годы возрастает роль технологий секвестрации $\mathrm{CO}_{2}$, как ключевого направления в обеспечении глобальной цели по предотвращению изменения климата. Данные технологии позволяют улавливать $\mathrm{CO}_{2}$, выделяемый в энергоемких производственных прочессах, тем самым предотвращая его попадание в атмосферу. Применение технологий секвестрации $\mathrm{CO}_{2}$ осуществляется в рамках $C C(U) S$ (carbon capture, utilization and storage) проектов, предполагающих захват, а в некоторых случаях использование и захоронение $\mathrm{CO}_{2}$.

Мировой опыт внедрения $C C(U) S$ технологий свидетельствует об их экологической результативности, однако повсеместному тиражсиованию $C C(U) S$ проектов препятствует ряд экономических, технических и организачионных ограничений. В условиях существвуюших барьеров актуальным признается формирование стратегического подхода, направленного на гармонизацию интересов по отношению к технологиям секвестрачии $\mathrm{CO}_{2}$ в системе «государство - бизнес - общество», что позволит ускорить их внедрение в различных секторах экономики.

Целью данного исследования является обоснование значимости участия государства в распространении $C C(U) S$ технологий, а также анализ перспектив применения существующих инструментов государственного регулирования развития технологий секвестрации $\mathrm{CO}_{2}$ при реализащии $C C(U) S$ проектов в России.

Основные результаты исследования представлены в виде систематизации существуюших в мировой практике инструментов государственного регулирования реализачии $C C(U) S$ проектов, оченки их применимости в России, а также комплекса рекомендаций для распространения российских CC(U)S проектов. Основными методами исследования выступали такие методы, как декомпозиция, систематизаџия и классификаџия, карта аргументов с ориентацией на актуальные практические материалы по тематике работы.

Ключевые слова: углекислый газ; секвестрации $\mathrm{CO}_{2}$; государственное регулирование; $C C(U) S$ проекты.

\section{THE STATE AS A KEY STAKEHOLDER IN THE PROSPECTS OF IMPLEMENTATION OF CC(U)S PROJECTS IN RUSSIA}

\author{
(C) 2020 N. V. Romasheva, A. A. Ilinova, O. O. Evseeva
}

\section{Saint Petersburg Mining University, Saint-Petersburg, Russia}

1 Исследование выполнено за счет гранта Российского научного фонда (проект №18-18-00210 «Разработка методологии оценки общественной эффективности проектов секвестрации углекислого газа»). 
The problem of reducing carbon dioxide $\left(\mathbf{C O}_{2}\right)$ emissions is today widely discussed throughout the world. In recent years, the role of $\mathrm{CO}_{2}$ sequestration technologies has been increasing as a key area in the strategy of the global mitigation goal. These technologies capture $\mathrm{CO}_{2}$ emitted from energy-intensive industrial processes, thereby preventing it from entering the atmosphere. The application of $\mathrm{CO}_{2}$ sequestration technologies is carried out in $\mathrm{CC}(\mathrm{U}) \mathrm{S}$ (carbon capture, use and storage) projects involving capture, in some cases use of $\mathrm{CO}_{2}$ and storage.

The world experience in the implementation of $C C(U) S$ technologies proves their environmental performance, however, the widespread replication of $C C(U) S$ projects is hampered by a number of economic, technical and organizational constraints. In the context of existing barriers, the formation of a strategic approach aimed at harmonizing interests in relation to $\mathrm{CO}_{2}$ sequestration technologies in the "state - business - society" system is recognized as relevant, which will accelerate their implementation in various sectors of the economy.

The purpose of this study is to substantiate the importance of state participation in the spreading of CC(U)S technologies, as well as to analyze the prospects for using existing instruments of state regulation of the development of $\mathrm{CO}_{2}$ sequestration technologies in the implementation of Russian CC(U)S projects.

The main results of the study are presented in the form of a systematization of existing instruments of state regulation of the development of the $C C(U) S$ direction, an assessment of their applicability in Russia, as well as a set of recommendations for the development of Russian CC(U)S projects. The main research methods were such methods as decomposition, systematization and classification, a map of arguments with a focus on relevant practical materials on the topic of the work.

Key words: carbon dioxide; $\mathrm{CO}_{2}$ sequestration; state regulation; $C C(U) S$ projects.

Введение. Изменение климата и глобальное потепление, по мнению многих ученых, связаны с увеличением в атмосфере Земли количества парниковых газов, включая $\mathrm{CO}_{2}$. Диоксид углерода является наиболее распространенным парниковым газом, который поступает в атмосферу как из естественных источников, так и антропогенных [1].

По данным компании ВР, объем выбросов $\mathrm{CO}_{2}$ в мире в 2018 году достиг своего максимума (33,9 млрд. т), увеличившись на $2,1 \%$, что является максимальным темпом роста за предшествующие 7 лет [9]. Наибольшая часть выбросов приходится на сектор транспорта (28\%), далее следуют сектор электроэнергетики (27\%) и промышленность (22\%) [20]. Россия занимает четвертое место в мире по объемам выбросов (1,55 млрд. т в 2018 году $4,5 \%$ от общемировых) после Китая $(27,8 \%)$, США $(15,1 \%)$ и Индии $(7,2 \%)[9]$.

Снижение количества выбросов $\mathrm{CO}_{2}$ является сегодня значимой задачей глобального уровня. Изменение климата представляет собой не только масштабную экологическую проблему, но и способствует разнонаправ- ленным изменениям во многих отраслях промышленности, тем самым влияя на мировую экономику [3]. Необходимость поиска путей минимизации негативного влияния на климатическую систему и разработки скоординированных стратегий выступила катализатором для активизации процессов международного сотрудничества в этой области. Глобальные механизмы, разрабатываемые в целях предотвращения изменений климата, формируют одновременно дополнительные обязательства и возможности для повышения конкурентных преимуществ среди стран, нацеленных на устойчивое развитие.

В условиях тенденции к декарбонизации заметное место занимают технологии секвестрации $\mathrm{CO}_{2}$. Международное энергетическое агентство и Международная группа экспертов $\mathrm{OOH}$ по изменению климата признают, что без крупномасштабного распространения данных технологий реализация целей по сокращению выбросов не представляется возможной [22].

Технологии секвестрации постепенно внедряются по всему миру на предприятиях 
различных отраслей промышленности [7]. По оценкам аналитиков, вклад технологий секвестрации $\mathrm{CO}_{2}$ в снижение концентрации $\mathrm{CO}_{2}$ в мировом масштабе к 2050 г. должен составлять не менее $13 \%$ [12].

Секвестрация $\mathrm{CO}_{2}$ позволяет улавливать до 90\% выбросов двуокиси углерода, образующихся в крупномасштабных энергоемких процессах, таких как производство цемента и стали, химическая обработка, производство водорода и выработка электроэнергии, предотвращая эмиссию вещества в атмосферу [22].

Секвестрация $\mathrm{CO}_{2}$ представляет собой совокупность технологий, которые можно разделить на три группы: улавливание и хра- нение углерода (carbon capture and storage CCS); улавливание и использование углерода (carbon capture and utilization - $\mathrm{CCU}$ ); улавливание, использование и захоронение (carbon capture, utilization and storage CCUS) [21]. Технологии CCS связаны с улавливанием и захоронением углекислого газа в геологических формациях и водоносных структурах. Технологии CCUS и CCU предполагают использование $\mathrm{CO}_{2}$, что позволяет получить коммерческий эффект. Направлениями использования $\mathrm{CO}_{2}$ в проектах CCUS являются повышение нефте- и газоотдачи, извлечение метана из угольных пластов, извлечение жидких минеральных ресурсов

\section{Концептуальное представление особенностей развития проектов $\mathrm{CC}(\mathrm{U}) \mathrm{S}$ (составлено авторами)} Таблица 1

\begin{tabular}{|c|c|c|c|}
\hline Показатель & Проекты CCS & Проекты CCUS & Проекты CCU \\
\hline $\begin{array}{l}\text { Сущность } \\
\text { проекта }\end{array}$ & $\begin{array}{l}\text { Захват и } \\
\text { захоронение } \mathrm{CO}_{2}\end{array}$ & $\begin{array}{l}\text { Захват, захоронение } \\
\text { и использование } \mathrm{CO}_{2}\end{array}$ & $\begin{array}{l}\text { Захват и } \\
\text { использование } \mathrm{CO}_{2}\end{array}$ \\
\hline $\begin{array}{l}\text { Цель } \\
\text { реализации }\end{array}$ & $\begin{array}{l}\text { Экологический эффект } \\
\text { Повышение имиджа стра- } \\
\text { ны и участников } \\
\text { Доступ к технологиям и } \\
\text { информации }\end{array}$ & \multicolumn{2}{|c|}{$\begin{array}{l}\text { Коммерческий эффект (при возможности) } \\
\text { Инновационно-технологическое развитие } \\
\text { производств } \\
\text { Экологический эффект } \\
\text { Ответственное инвестирование } \\
\text { Повышение имиджа участников }\end{array}$} \\
\hline $\begin{array}{l}\text { Ранжирование } \\
\text { ключевых } \\
\text { участников* }\end{array}$ & $\begin{array}{l}\text { 1. Государство } \\
\text { 2. Общество } \\
\text { 3. Бизнес }\end{array}$ & $\begin{array}{l}\text { 1. Бизнес } \\
\text { 2. Государство } \\
\text { 3. Общество }\end{array}$ & $\begin{array}{l}\text { 1. Бизнес } \\
\text { 2. Государство }\end{array}$ \\
\hline $\begin{array}{l}\text { Экономические } \\
\text { аспекты }\end{array}$ & $\begin{array}{l}\text { Не являются коммерчес- } \\
\text { кими, высокий уровень } \\
\text { капитальных и эксплуа- } \\
\text { тационных затрат, отсутс- } \\
\text { твие дохода }\end{array}$ & \multicolumn{2}{|c|}{$\begin{array}{l}\text { Возможно получение коммерческого эффек- } \\
\text { та, однако, величина капитальных и эксплуа- } \\
\text { тационных затрат на текущем уровне разви- } \\
\text { тия технологий достаточно велика и может } \\
\text { быть не сопоставима с доходами }\end{array}$} \\
\hline $\begin{array}{l}\text { Технологические } \\
\text { аспекты }\end{array}$ & $\begin{array}{l}\text { Технологический цикл } \\
\text { апробирован, особое вни- } \\
\text { мание к захоронению и } \\
\text { мониторингу хранилищ }\end{array}$ & $\begin{array}{l}\text { Техн ологический } \\
\text { цикл в стадии апро- } \\
\text { бации и масштаби- } \\
\text { рования, особое вни- } \\
\text { мание к технологиям } \\
\text { использования } \mathrm{CO}_{2} \text {, } \\
\text { захоронению и мони- } \\
\text { торингу хранилищ }\end{array}$ & $\begin{array}{l}\text { Техн ологиче с ки й } \\
\text { цикл в стадии разви- } \\
\text { тия, особое внимание } \\
\text { к технологиям ис- } \\
\text { пользования } \mathrm{CO}_{2}\end{array}$ \\
\hline $\begin{array}{l}\text { Социальные } \\
\text { аспекты }\end{array}$ & \multicolumn{3}{|c|}{$\begin{array}{l}\text { Снижение выбросов в регионе, социальные инвестиции в развитие реги- } \\
\text { она, создание новых рабочих мест }\end{array}$} \\
\hline
\end{tabular}


и воды. Направлениями использования $\mathrm{CO}_{2}$ в проектах CCU являются производство углеродных видов топлива, химических веществ, строительных материалов, а также использование $\mathrm{CO}_{2}$ для повышения урожайности.

В таблице 1 представлено концептуальное видение и анализ особенностей развития проектов с выделением сущности и цели реализации, а также определением характе- ристик по экономическим, технологическим и социальным аспектам.

$\mathrm{CC}(\mathrm{U}) \mathrm{S}$ проекты дают возможность гибкого перехода к снижению выбросов. В отличие от более радикальных механизмов декарбонизации (отказа от использования органического топлива, перехода на альтернативную энергетику и пр.), они не требуют замены глобальной инфраструктуры и подде-

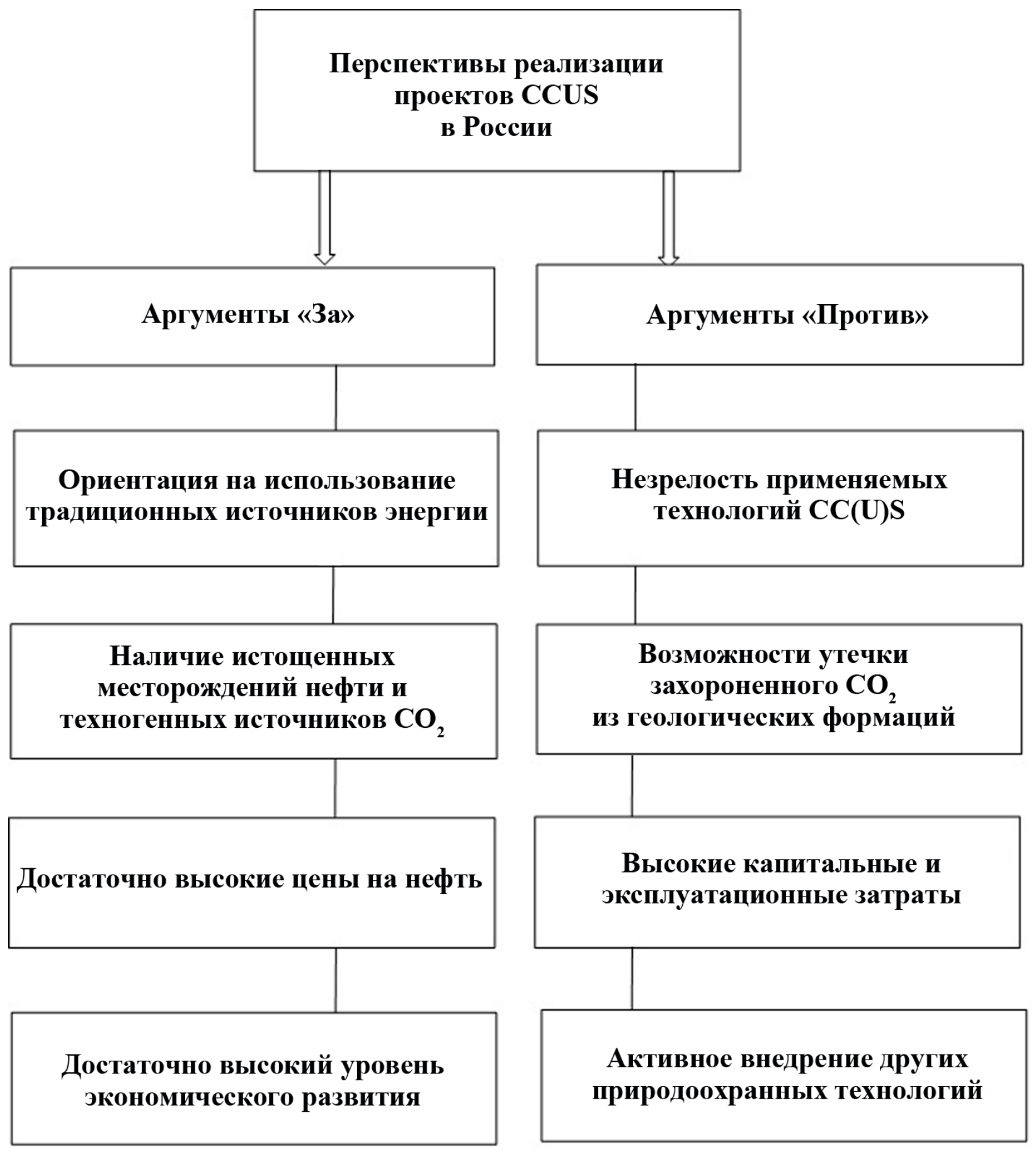

Рис. 1. Аргументационная карта реализации проектов $\mathrm{CC}(\mathrm{U}) \mathrm{S}$ в России (составлено авторами) 
рживают отрасли, сохраняя тем самым рабочие места и налоговые поступления [22].

Роль государства в развитии технологий секвестрации $\mathrm{CO}_{2}$. При текущем уровне развития технологий секвестрации $\mathrm{CO}_{2}$ государственное регулирование играет определяющую роль для активизации развития $\mathrm{CC}(\mathrm{U}) \mathrm{S}$ проектов; их распространение требует целенаправленного политического вмешательства через механизмы популяризации и поддержки, а также систему стимулов и ограничений $[4,5]$. В странах, занимающих активную позицию по вопросу снижения эмиссии $\mathrm{CO}_{2}$, общепризнанным является тот факт, что государственное участие имеет решающее значение для обеспечения того, чтобы проекты $\mathrm{CC}(\mathrm{U}) \mathrm{S}$ инициировались, геологическое хранение $\mathrm{CO}_{2}$ было безопасным и эффективным, природные ресурсы эффективно использовались, бизнес проявлял интерес к таким проектам, а общество признавало эту технологию $[6,8]$.
На данный момент времени на территории Российской Федерации не реализуется ни один из $\mathrm{CC}(\mathrm{U}) \mathrm{S}$ проектов, однако по ряду причин их внедрение является перспективным (рисунок 1).

В существующей литературе $[10,11,13$, $14,15,16,17,18,24]$, а также в ранее проведенных авторами исследованиях [19] было выявлено, что государственное регулирование эмиссии парниковых газов имеет определяющее значение в распространении технологий секвестрации $\mathrm{CO}_{2}$. При этом роль государства в экологическом развитии должна быть представлена как побуждающими, так и поддерживающими механизмами.

Участие государства в широкомасштабном распространении технологий $\mathrm{CC}(\mathrm{U}) \mathrm{S}$ должно быть направлено одновременно на снижение существующих барьеров и стимулирование хозяйствующих субъектов к использованию технологий CC(U)S. Ключевыми барьерами для начала реализации проектов секвестрации $\mathrm{CO}_{2}$ сегодня являются высокие капитальные

\section{Направления деятельности государства в распространении технологий секвестрации $\mathrm{CO}_{2}$ (составлено авторами)}

\begin{tabular}{|c|c|}
\hline $\begin{array}{c}\text { Направление } \\
\text { государственной политики }\end{array}$ & Содержание \\
\hline $\begin{array}{l}\text { Транслирование привержен- } \\
\text { ности сокращению выбро- } \\
\text { сов парниковых газов }\end{array}$ & $\begin{array}{l}\text { Ориентир на сокращение эмиссии } \mathrm{CO}_{2} \text { в масштабах всей на- } \\
\text { циональной экономики, государственные программы развития } \\
\text { технологий } \mathrm{CC}(\mathrm{U}) \mathrm{S}\end{array}$ \\
\hline $\begin{array}{l}\text { Поддержка операционной } \\
\text { эффективности } \\
\text { технологий CC(U)S }\end{array}$ & $\begin{array}{l}\text { Предоставление налоговых преференций участникам CC(U)S } \\
\text { проектов. Минимизация рисков, в т.ч. связанных с реализацией } \\
\text { продукции, производимой с применением CCUS }\end{array}$ \\
\hline $\begin{array}{l}\text { Информационное } \\
\text { сопровождение }\end{array}$ & $\begin{array}{l}\text { Масштабное распространение в обществе информации о содер- } \\
\text { жании технологии CC(U)S; содействие повышению ее имиджа }\end{array}$ \\
\hline $\begin{array}{l}\text { Нормативное } \\
\text { регулирование }\end{array}$ & $\begin{array}{l}\text { Устранение правовых барьеров в развитии индустрии CC(U)S, } \\
\text { стимулирование производственного сектора к сокращению } \\
\text { эмиссии парниковых газов путем введения установленных ог- } \\
\text { раничений по объемам выбросов }\end{array}$ \\
\hline $\begin{array}{l}\text { Государственное } \\
\text { финансирование }\end{array}$ & $\begin{array}{l}\text { Целевое финансирование научных исследований и разработок } \\
\text { в сфере сокращения эмиссий } \mathrm{CO}_{2} \text {, государственные инвест- } \\
\text { ции в инфраструктуру } \mathrm{CC}(\mathrm{U}) \mathrm{S}\end{array}$ \\
\hline $\begin{array}{l}\text { Международное } \\
\text { сотрудничество }\end{array}$ & $\begin{array}{l}\text { Содействие созданию условий для обмена передовым опытом } \\
\text { в области сокращения эмиссий парниковых газов; развитие } \\
\text { международной интеграции в рамках совместного осуществле- } \\
\text { ния проектов }\end{array}$ \\
\hline
\end{tabular}


и операционные затраты, значительные коммерческие, технические и организационные риски $\mathrm{CC}(\mathrm{U}) \mathrm{S}$ проектов, низкая осведомленность общества о преимуществах данных технологий, противодействие со стороны природоохранных организаций $[2,23]$. В связи с этим целесообразно выделить следующие основополагающие направления политики государства в данной области (таблица 2).

Технологии секвестрации требуют инвестиций как на стадии разработки, так и на стадии внедрения на объектах, способствуют возникновению дополнительных рисков, тем самым повышая привлекательность

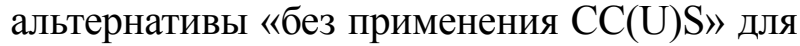
хозяйствующих субъектов. В отсутствии прямого экономического эффекта (например, для технологий $\mathrm{CCS}$ ), принятие решения в пользу технологии в большинстве случаев будет связано с необходимостью выполнения установленных требований.

Процесс реализации $\mathrm{CC}(\mathrm{U}) \mathrm{S}$ проектов до момента их выхода на эксплуатационную стадию может быть достаточно продолжительным. Даже в случае наличия у проектов коммерческого эффекта длительный период окупаемости и отсутствие проектов-аналогов может негативно отразиться на принятии инвестиционного решения. Поддержка государством подобных инициатив помимо прямых экологических результатов позволит получить эффекты, связанные с заинтересованностью бизнеса в реализации российских проектов секвестрации $\mathrm{CO}_{2}$, в том числе с применением отечественных технологий.

Государственное регулирование развития CC(U)S проектов. По мнению Global CCS Institute, комплексная нормативно-правовая основа для поддержки расширения масштабов CCS в мире пока не разработана [12]. При этом отмечается, что в отсутствие последовательной государственной политики частный сектор не будет внедрять технологии секвестрации в объеме, необходимом для достижения целей по смягчению последствий изменения климата [12]. В работе [19] доказано, что успешность реализации $\mathrm{CC}(\mathrm{U}) \mathrm{S}$ проектов в ведущих странах мира, таких как США, Канада, Великобритания, Япония, Китай и др., напрямую зависит от разнообразия создан- ной нормативно-правовой базы, используемых методов стимулирования.

Практическая значимость государственной политики определяется инструментами государственного регулирования, влияющими на функционирование конкретной системы. Авторами настоящего исследования был проанализирован перечень потенциально возможных инструментов государственного регулирования развития направления $\mathrm{CC}(\mathrm{U}) \mathrm{S}$ в России. Результат анализа представлен в таблицах 3 и 4.

Административные механизмы регулирования активно используется с целью охраны окружающей среды. Различные законодательные акты, стандарты, регулирующие выбросы вредных веществ, препятствующие образованию и складированию отходов производства, прямые запреты на использование опасных технологий ограничивают свободу компаний. С помощью экономических инструментов государственные структуры воздействуют на компании с целью обеспечения их необходимого поведения путем воздействия на материальные интересы. При этом экономические и административные инструменты государственного регулирования взаимосвязаны. Так, любой инструмент, относящийся к экономическим, несет в себе элементы администрирования, поскольку контролируется той или иной государственной структурой. По нашему мнению, особое внимание должно уделяться организационным инструментам государственного регулирования, поскольку они формируют эффективные институциональные условия, способствующие внедрению и распространению $\mathrm{CC}(\mathrm{U}) \mathrm{S}$ проектов.

Применение широкого спектра инструментов государственного регулирования развития $\mathrm{CC}(\mathrm{U}) \mathrm{S}$ проектов допустимо, однако проведенные исследования по данной проблеме показали, что первоочередное значение для компаний, инвестирующих в $\mathrm{CC}(\mathrm{U}) \mathrm{S}$ проекты, имеют экономические инструменты, а также предсказуемость и гибкость нормативно-правовой базы.

На основе анализа зарубежного опыта государственного регулирования $\mathrm{CC}(\mathrm{U}) \mathrm{S}$ проектов, а также изучения законодательства об охране окружающей среды авторами сформулированы рекомендации по созданию 
политической и нормативной базы, стимулирующей реализацию и распространение $\mathrm{CC}(\mathrm{U}) \mathrm{S}$ проектов. Данные рекомендации даны по группам инструментов государственного регулирования и включают следующее.

1. Административные инструменты. В России приняты основополагающие законы по охране окружающей среды, установлены нормативы допустимого воздействия на окружающую среду, однако нарушение нормативов нефтегазовыми компаниями пока еще не приводит к серьезным финансовым потерям. В целях охраны окружающей среды и распространения $\mathrm{CC}(\mathrm{U}) \mathrm{S}$ проектов необходимо постепенно ужесточать существующее законодательство.

Таблица 3

\section{Инструменты государственного регулирования развития CC(U)S проектов (составлено авторами)}

\begin{tabular}{|c|c|}
\hline Инструменты государственного регулирования & $\begin{array}{c}\text { Для } \\
\mathrm{CC}(\mathrm{U}) \mathrm{S} \\
\text { проектов } \\
\text { России* }\end{array}$ \\
\hline \multicolumn{2}{|l|}{ Экономические } \\
\hline 1. Парижское соглашение о климате & V \\
\hline $\begin{array}{l}\text { 2. Климатическая и энергетическая политика государства (дорожные карты сни- } \\
\text { жения выбросов) }\end{array}$ & $\mathrm{V}$ \\
\hline $\begin{array}{l}\text { 3. Государственные программы, стратегии реализации проектов CCS, дорожные } \\
\text { карты по сокращению выбросов } \mathrm{CO}_{2}\end{array}$ & $\mathrm{~V}$ \\
\hline 4. Налог на выбросы $\mathrm{CO}_{2}$ & $\mathrm{X}$ \\
\hline 5. Налоговые льготы для компаний, реализующих проекты CCS & $\mathrm{V}$ \\
\hline 6. Налоговый кредит & $\mathrm{V}$ \\
\hline 7. Схемы торговли выбросами & $\mathrm{X}$ \\
\hline \multicolumn{2}{|l|}{ Административные } \\
\hline 8. Специфические законы, связанные с улавливанием и захоронением $\mathrm{CO}_{2}$ & $\mathrm{~V}$ \\
\hline 9. Экологическое законодательство (законы о качестве воды, воздуха и об отходах) & $\mathrm{V}$ \\
\hline 10. Стандарт, ограничивающий концентрацию $\mathrm{CO}_{2}$ в газе & $\mathrm{X}$ \\
\hline $\begin{array}{l}\text { 11. Прямая финансовая поддержка реализации проектов CC(U)S различными го- } \\
\text { сударственными фондами и структурами }\end{array}$ & $\mathrm{V}$ \\
\hline $\begin{array}{l}\text { 12. Государственная поддержка научно-исследовательских и опытно конструк- } \\
\text { торских работ }\end{array}$ & $\mathrm{V}$ \\
\hline \multicolumn{2}{|l|}{ Организационные } \\
\hline 13. Межправительственное международное сотрудничество по проектам CCS & $\mathrm{V}$ \\
\hline 14. Процесс выдачи разрешений на хранение $\mathrm{CO}_{2}$ & $\mathrm{~V}$ \\
\hline 15. Государственные институты и организации по продвижению технологий CCS & $\mathrm{V}$ \\
\hline 16. Предсказуемая правовая база & $\mathrm{V}$ \\
\hline $\begin{array}{l}\text { 17. Государственные программы по продвижению экологически ответственного } \\
\text { бизнеса }\end{array}$ & $\mathrm{V}$ \\
\hline 18. Средства обучения на всех уровнях образования & $\mathrm{V}$ \\
\hline \multicolumn{2}{|c|}{$\begin{array}{l}\text { * V - инструмент может быть использован для условий России; X - не целесообразно ис- } \\
\text { пользовать для условий России }\end{array}$} \\
\hline
\end{tabular}




\section{Характеристика инструментов государственного регулирования развития $\mathrm{CC}(\mathrm{U}) \mathrm{S}$ проектов (составлено авторами)}

\begin{tabular}{|c|c|}
\hline № & Сущность \\
\hline \multicolumn{2}{|c|}{ Экономические } \\
\hline 1 & $\begin{array}{l}\text { Регулируют меры по снижению содержания } \mathrm{CO}_{2} \text { в атмосфере с } 2020 \text { года, ратификация } \\
\text { соглашения способствует реализации любых типов проектов } \mathrm{CC}(\mathrm{U}) \mathrm{S} \text {, в свою очередь, } \\
\text { выход из соглашения может оказать негативное влияние на их интенсификацию }\end{array}$ \\
\hline 2 & $\begin{array}{l}\text { Имеют существенное значение для распространения любых типов проектов } \mathrm{CC}(\mathrm{U}) \mathrm{S} \text {, } \\
\text { если в данных документах отражены цели и разработаны мероприятия по сокращению } \\
\text { выбросов парниковых газов }\end{array}$ \\
\hline 3 & $\begin{array}{l}\text { Стимулируют реализацию и распространение любых типов проектов } \mathrm{CC}(\mathrm{U}) \mathrm{S} \text { в случае } \\
\text { их понятной и четкой формулировки, а также соответствия стратегической и климати- } \\
\text { ческой политике }\end{array}$ \\
\hline 4 & $\begin{array}{l}\text { Являются эффективным механизмом сокращения выбросов } \mathrm{CO}_{2} \text { во многих странах } \\
\text { мира и стимулом к реализации любых природоохранных проектов, однако оказывают } \\
\text { негативное влияние на коммерческую эффективность деятельности компаний и не це- } \\
\text { лесообразен к применению в России }\end{array}$ \\
\hline 5 & $\begin{array}{l}\text { Применяются во многих странах для стимулирования реализации демонстрационных } \\
\text { проектов CC(U)S, не предусматривающих получение дополнительных экономических } \\
\text { эффектов }\end{array}$ \\
\hline 6 & $\begin{array}{l}\text { Предоставляются только в США, что связано с развитой системой законодательства в } \\
\text { данной стране и сложностью использования данного механизма в случае, если улавли- } \\
\text { вание и захоронение } \mathrm{CO}_{2} \text { осуществляется разными компаниями }\end{array}$ \\
\hline 7 & $\begin{array}{l}\text { Могут рассматриваться как эффективный механизм стимулирования реализации проек- } \\
\text { тов CCS, согласно которому устанавливаются обязательства по сокращению выбросов } \\
\text { для участников рынка и распределяются квоты на выбросы, которые могут покупать- } \\
\text { ся участниками с целью компенсации чрезмерных выбросов или продаваться в случае } \\
\text { соблюдения экологических нормативов. В России данный механизм не планируется к } \\
\text { применению в среднесрочной перспективе в связи с отсутствием утвержденных док-- } \\
\text { ментов, определяющих процедуры и правила торговли квотами }\end{array}$ \\
\hline \multicolumn{2}{|c|}{ Административньее } \\
\hline 8 & $\begin{array}{l}\text { Регулируют транспортировку, наземное и морское хранение } \mathrm{CO}_{2} \text {, устанавливают пра- } \\
\text { вила и порядок оценки объема возможного захоронения } \mathrm{CO}_{2} \text {. Только в некоторых стра- } \\
\text { нах данные законы создают четкую правовую основу и не противоречат другим законо- } \\
\text { дательным актам, регулирующим разведку и добычу углеводородов, хранение природ- } \\
\text { ного газа, добычу питьевой воды и т.д. }\end{array}$ \\
\hline 9 & $\begin{array}{l}\text { Действуют во многих странах мира и стимулируют компании к внедрению природо- } \\
\text { охранных технологий, в том числе всех видов технологий улавливания и захоронения } \\
\mathrm{CO}_{2} \text {, за счет высоких штрафов за его нарушение }\end{array}$ \\
\hline 10 & $\begin{array}{l}\text { Действуют на территории некоторых добывающих углеводороды государств, что де- } \\
\text { лает необходимым удаление газа во время обработки и его полезное использование и } \\
\text { приводит к необходимости реализации любых типов проектов CC(U)S }\end{array}$ \\
\hline
\end{tabular}


Окончание таблицы 4

\begin{tabular}{|c|c|}
\hline 11 & $\begin{array}{l}\text { Имеют решающее значение для развития и распространения низкоуглеродных техно- } \\
\text { логий. Большинство проектов были поддержаны государственными структурами раз- } \\
\text { ных уровней управления. Важен баланс между государственной поддержкой и инвес- } \\
\text { тициями бизнеса. Для проектов CCUS государственная поддержка на коммерческой } \\
\text { стадии нецелесообразна }\end{array}$ \\
\hline 12 & $\begin{array}{l}\text { Являются обязательным условиям для внедрения технологий } \mathrm{CC}(\mathrm{U}) \mathrm{S} \text {. Такая поддержка } \\
\text { направлена на снижение рисков и затрат, и в то же время увеличение доступных ресурсов }\end{array}$ \\
\hline \multicolumn{2}{|c|}{ Организачиоонные } \\
\hline 13 & $\begin{array}{l}\text { Играют важную роль в обмене опытом и распространении технологий CC(U)S по все- } \\
\text { му миру. Правительства многих стран предоставляют финансирование для проектов } \\
\mathrm{CC}(\mathrm{U}) \mathrm{S} \text { в сотрудничестве с другими странами и через существующие программы и } \\
\text { учреждения }\end{array}$ \\
\hline 14 & $\begin{array}{l}\text { Являются критически важной нормативной проблемой, с которой сталкиваются компа- } \\
\text { нии, реализующие проекты CC(U)S в различных регионах мира. Многие проекты по } \\
\text { всему миру были отложены или отменены из-за сложного процесса выдачи разреше- } \\
\text { ний на хранение } \mathrm{CO}_{2}\end{array}$ \\
\hline 15 & $\begin{array}{l}\text { Действуют во многих странах мира и способствуют ускорению развития проектов CC(U)S. } \\
\text { Создавая различные источники информации, такие учреждения могут иметь решающее } \\
\text { значение для информирования общественности и восприятия технологий CCS(U) }\end{array}$ \\
\hline 16 & $\begin{array}{l}\text { Необходимы для развертывания CC(U)S технологий, как на национальном, так и на } \\
\text { международном уровне. Из-за широкого спектра индивидуальных и уникальных усло- } \\
\text { вий в каждом проекте CC(U)S важно иметь гибкое, но предсказуемое законодательство }\end{array}$ \\
\hline 17 & $\begin{array}{l}\text { Побуждают компании рассматривать экологически ответственный бизнес как часть } \\
\text { своей деятельности, что стимулирует реализацию природоохранных мер, включая про- } \\
\text { екты } C C(U) S\end{array}$ \\
\hline 18 & $\begin{array}{l}\text { Обеспечивают школьников и студентов знаниями о существующих экологических про- } \\
\text { блемах и путей их решения, способствуют осознанию важности и роли проектов CC()S } \\
\text { в устойчивом развитии }\end{array}$ \\
\hline
\end{tabular}

Перед началом реализации $\mathrm{CC}(\mathrm{U}) \mathrm{S}$ проектов следует создать не противоречащее законодательство, регулирующее улавливание, захват, захоронение, утилизацию и транспортировку $\mathrm{CO}_{2}$. Отсутствие специального законодательства может стать поводом для переноса или отмены таких проектов. На данный момент времени специфические законы, регулирующие реализацию проектов CCS, в России не приняты.

Низкая коммерческая эффективность, сложность технологий, высокие капитальные и операционные затраты делают финансовую поддержку решающей на начальном этапе реализации $\mathrm{CC}(\mathrm{U}) \mathrm{S}$ проектов. Сегод- ня в России предусмотрена государственная поддержка для региональных инвестиционных проектов, специальных инвестиционных контрактов и т.д., однако в связи с отсутствием в планах реализации проектов $\mathrm{CC}(\mathrm{U}) \mathrm{S}$ финансовая поддержка для них пока не планируется. Также не осуществляется финансирование НИОКР в области исследования технологий улавливания и захоронения $\mathrm{CO}_{2}$, тем не менее, за счет средств различных бюджетов покрываются затраты на исследования и разработки по приоритетным направлениям развития науки, технологий и техники. Для успешной реализации $\mathrm{CC}(\mathrm{U}) \mathrm{S}$ проектов, в первую очередь, важно создать адрес- 
ные, стабильные, сбалансированные и динамичные программы финансовой поддержки $\mathrm{CC}(\mathrm{U})$ технологий, чтобы обеспечить уверенность инвесторов и преодолеть высокие первоначальные затраты.

2. Экономические инструменты. Россия ратифицировала Парижское соглашение 23 сентября 2019 года, однако реальных механизмов по снижению выбросов $\mathrm{CO}_{2}$ до сих пор не разработано. В России принята Энергетическая стратегия, однако вопросы снижения выбросов $\mathrm{CO}_{2}$ не относятся к числу приоритетных направлений развития энергетики; большое внимание уделяется перспективам использования альтернативных источников энергии. Для внедрения и реализации $\mathrm{CC}(\mathrm{U})$ проектов необходимо включить цель по сокращению выбросов $\mathrm{CO}_{2}$ и соответствующие инициативы в энергетическую стратегию, а также разработать дорожные карты на государственном уровне.

В налоговом кодексе России предусмотрен широкий спектр налоговых льгот при освоении нефтегазовых месторождений. Целесообразным является предусмотреть льготные ставки при исчислении налога на добычу нефти, полученной в результате повышения коэффициента нефтеотдачи за счет использования $\mathrm{CO}_{2}$.

В России инвестиционный налоговый кредит предоставляется на срок до 5, в ряде случаев до 10 лет, однако применяется он только для налога на прибыль, а также региональных и местных налогов. Целесообразным представляется применение налогового кредита также для $\mathrm{CC}(\mathrm{U}) \mathrm{S}$ проектов.

3. Организационные инструменты. Для распространения CC(U)S проектов необходимо предусмотреть участие в международных программах и проектах, создать эффективный механизм выдачи разрешений на захоронение $\mathrm{CO}_{2}$, повышать информированность общественности, взаимодействовать с неправительственными организациями, стимулировать компании к экологически ответственной деятельности, а также создать систему для результативного скоординированного взаимодействия между компаниями, заинтересованными в реализации $\mathrm{CC}(\mathrm{U}) \mathrm{S}$ проектов.

Заключение. Проекты секвестрации $\mathrm{CO}_{2}$ являются стратегическими и с момента их инициации (при должной государственной поддержке, нормативно-правовой базе и применении мер административного характера) будут реализовываться на протяжении десятков лет. При этом некоторые виды таких проектов по своей природе не являются коммерческими. Наряду с возможностью генерации дохода по мере развития технологий важной представляется экологическая и социальная направленность, а также роль $\mathrm{CC}(\mathrm{U}) \mathrm{S}$ проектов в формировании экологически направленного сознания общества. Это определяет необходимость применения совершенно иных подходов к управлению ими как на уровне хозяйствующего субъекта, так и на уровне государства.

В результате проведенного исследования авторами получены следующие результаты.

1. Обоснована значимость участия государства в развитии направления CC(U)S. Bыявлены, систематизированы и охарактеризованы инструменты государственного регулирования развития $\mathrm{CC}(\mathrm{U}) \mathrm{S}$ проектов. Новизна результатов заключается в представлении списка таких инструментов, их классификации и определении возможности применения в условиях России. В ранее проведенных зарубежных исследованиях рассматривались либо отдельные инструменты государственного регулирования, либо был представлен ограниченный их перечень без сущности. Применительно к России данный вопрос не исследовался, в ряде работ выполнен анализ инструментов государственного регулирования, применяемых в США, Норвегии, Европе. Однако, представленное в работе деление инструментов на административные, экономические и организационные носит дискуссионный характер и требует дальнейшего более тщательного обоснования с определением степени важности для каждого типа $\mathrm{CC}(\mathrm{U})$ проекта.

2. По группам инструментов государственного регулирования разработаны рекомендации по созданию нормативно-правовой базы, стимулирующей реализацию и распространение $\mathrm{CC}(\mathrm{U}) \mathrm{S}$ проектов в России. Для условий России ранее такие исследования не проводились, однако данные рекомендации носят скорее общий характер и будут детализированы в дальнейших исследованиях. 


\section{Литература}

1. Голубева А.С., Магарил Е.Р. Обоснование необходимости сокращения эмиссии $\mathrm{CO}_{2}$ автомобильным транспортом // Вестник УРФУ. Серия: Экономика и управление. 2012. — №2. - C. 109-117.

2. Евсеева О.О., Ильинова А.А., Череповищын A. E. Согласование интересов ключевых стейкхолдеров при реализации проектов секвестрации $\mathrm{CO}_{2} / /$ Север и рынок: формирование экономического порядка. 2018. 一№4 (60). — С. 133-141.

3. Любарская М.А., Меркушева В.С., Зиновьева O.С. Участие России в международном сотрудничестве в сфере сокращения выбросов парниковых газов энергетическими компаниями // Вестник РУДН. Серия: Международные отношения. - 2019. - №3. С. 377-390.

4. Ромашева Н.В., Каблан И.Б.К. Зарубежный опыт нормативно-правового регулирования проектов улавливания и захоронения углекислого газа // Экономика и предпринимательство. — 2019. — №9 (110). — С. 864-868.

5. Ромашева Н.В., Крук М.Н., Череповиuзын A.E. Особенности мировых проектов секвестрации $\mathrm{CO}_{2} / /$ Российский экономический интернет-журнал. - 2018. — №4. - С. 97.

6. Череповицын А.Е. и др. Ключевые социально-экономические аспекты развития секвестрации углекислого газа: Монография. - СПб.: ЛЕМА, 2019. - 229 с.

7. Череповицын А.Е., Васильев Ю.Н., Цветкова А.Ю. Оценка перспектив внедрения технологий секвестрации $\mathrm{CO}_{2} / /$ РИСК: Ресурсы, Информация, Снабжение, Конкуренция. - 2018. - №2. - С. 86-89.

8. Череповицын А.Е., Ильинова А.А., Евсеева О.О. Управление стейкхолдерами проектов секвестрации углекислого газа в системе «государство - бизнес - общество»// Записки горного института. - 2019. T. 240. - C. 731-742.

9. BP: Statistical Review of World Energy 2019 edition [Электронный ресурс] - Режим доступа: https://nangs.org/analytics/bp-statistical-review-of-world-energy (Дата обращения: 12.08.2020).

10. Budinis S., Krevor S., Mac Dowell N., Brandon N., Hawkes A. An assessment of CCS costs, barriers and potential // Energy Strategy
Reviews. DOI: 10.1016/j.esr.2018.08.003. 2018. - Vol. 22. - Pp. 61-81.

11. Burton E., Ezzedine S., Reed J., Beyer J. Accelerating Carbon Capture and Sequestration Projects: Analysis and Comparison of Policy Approaches // Energy Procedia. 2011. - Vol. 4. - Pp. 5778-5785.

12. Global CCS Institute. Policy priorities to incentivise large scale deployment of CCS [Электронный ресурс] - Режим доступа: https://www.globalccsinstitute.com/resources/ publications-reports-research/policy-prioritiesto-incentivise-large-scale-deployment-of-ccs/ (Дата обращения: 01.09.2020).

13. Hasan M.F., First E.L., Boukouvala F., Floudas C.A. A multi-scale framework for $\mathrm{CO}_{2}$ capture, utilization, and sequestration: $\mathrm{CCUS}^{2}$ and CCU // Computer Aided Chemical Engineering. - 2015. - Vol. 81. - Pp. 2-21.

14. Henriksen D., Ombudstvedt I. CCS What Does it Take? Necessary Framework to Succeed with CCS // GHGT-12, Energy Procedia. DOI: 10.1016/j.egypro.2014.11.708. 2014. - Vol. 63. - Pp. 6730-6737.

15. Herzog H. Financing CCS Demonstration Projects: Lessons Learned from Two Decades of Experience // Energy Procedia. DOI: 10.1016/j.egypro.2017.03.1708. - 2017. Vol. 114. - Pp. 5691-5700.

16. Krahe M., Heidug W., Ward J., Smale R. From demonstration to deployment: An economic analysis of support policies for carbon capture and storage // Energy Policy. DOI: 10.1016/j. enpol.2013.05.019. - 2013. — Vol. 60. Pp. 753-763.

17. Lipponen J., McCulloch S., Keeling S., Stanley T., Berghout N., Berly T. The Politics of Large-scale CCS Deployment // Energy Procedia. DOI: https://doi.org/10.1016/j.egypro.2017.03.1890. - 2017. - Vol. 114. Pp. 7581-7595.

18. Mardones C., Baeza N. Economic and environmental effects of a $\mathrm{CO}_{2}$ tax in Latin American countries // Energy Policy. DOI: 10.1016/j. enpol.2017.12.001. - 2018. — Vol.114. Pp. 262-273.

19. Romasheva N., Ilinova A. CCS Projects: How Regulatory Framework Influences Their Deployment [Электронный pecypc] // Resources. - 2019. - Vol. 8(4), 181. - Режим доступа: https://doi. org/10.3390/resources 8040181 . 
20. Sources of Greenhouse Gas Emissions [Электронный ресурс] — Режим доступа: https://www.epa.gov/ghgemissions/sourcesgreenhouse-gas-emissions (Дата обращения: 10.09.2020).

21. Tcvetkov P.S., Cherepovitsyn A.E., Fedoseev $S$. $V$. The Changing Role of $\mathrm{CO}_{2}$ in the Transition to a Circular Economy: Review of Carbon Sequestration Projects // Sustainability. - 2019. - №11. - Pp. 1-19.

22. What Is Carbon Capture and Storage $(\mathrm{CCS})$ ? [Электронный ресурс] — Режим доступа: https://ccsknowledge.com/what-is-ccs (Дата обращения: 19.08.2020).

23. ZERO Policy instruments for largescale CCS [Электронный ресурс] — Режим доступа: https://www.zero.no/wp-content/ uploads/2016/06/policy-instruments-for-largescale-ccs.compressed.pdf (Дата обращения: 01.09.2020).

24. Zhao X., Yin H., Zhao Y. Impact of environmental regulations on the efficiency and $\mathrm{CO}_{2}$ emissions of power plants in China // Applied Energy. DOI: 10.1016/j.apenergy.2015.03.112. 2015. - Vol. 149. — Pp. 238-247.

\section{References}

1. Golubeva A.S., Magaril E.R. Obosnovanie neobhodimosti sokrashhenija jemissii $\mathrm{CO}_{2}$ avtomobil'nym transportom [Justification of the need to reduce $\mathrm{CO}_{2}$ emissions by road transport]// Vestnik URFU. Serija: Jekonomika i upravlenie [Urfu Bulletin. Series: Economics and management]. - 2012. — №2. - Pp. 109-117.

2. Evseeva O.O., Il'inova A. A., Cherepovicyn A. E. Soglasovanie interesov kljuchevyh stejkholderov pri realizacii proektov sekvestracii $\mathrm{CO}_{2}$ [Coordination of interests of key stakeholders in the implementation of $\mathrm{CO}_{2}$ sequestration projects] // Sever i rynok: formirovanie jekonomicheskogo porjadka [The North and the market: shaping the economic order]. 2018. —№4 (60). - Pp. 133-141.

3. Ljubarskaja M.A., Merkusheva V.S., Zinov'eva O.S. Uchastie Rossii v mezhdunarodnom sotrudnichestve v sfere sokrashhenija vybrosov parnikovyh gazov jenergeticheskimi kompanijami [Russia's Participation in international cooperation in reducing greenhouse gas emissions by energy companies] // Vestnik RUDN. Serija: Mezhdunarodnye otnoshenija [RUDN Bulle- tin. Series: International relations]. - 2019. №3. - Pp. 377-390.

4. Romasheva N.V., Kablan I.B.K. Zarubezhnyj opyt normativno-pravovogo regulirovanija proektov ulavlivanija i zahoronenija uglekislogo gaza [Foreign experience of regulatory regulation of carbon dioxide capture and disposal projects] // Jekonomika i predprinimatel'stvo [Economics and entrepreneurship]. - 2019. №9 (110). - Pp. 864-868.

5. Romasheva N. V., Kruk M.N., Cherepovicyn A.E. Osobennosti mirovyh proektov sekvestracii $\mathrm{CO}_{2}$ [Features of global $\mathrm{CO}_{2}$, sequestration projects] // Rossijskij jekonomicheskij internetzhurnal [Russian economic online journal]. 2018. - №4. - P. 97.

6. Cherepovicyn A.E. et al. Kljuchevye social'no-jekonomicheskie aspekty razvitija sekvestracii uglekislogo gaza: Monografija [Key socio-economic aspects of the development of carbon dioxide sequestration: Monograph]. Saint-Petersburg: LEMA, 2019. — 229 p.

7. CherepovicynA.E., Vasil'ev Ju. N., Cvetkova A. Ju. Ocenka perspektiv vnedrenija tehnologij sekvestracii $\mathrm{CO}_{2}$ [Assessment of prospects for implementing $\mathrm{CO}_{2}$ sequestration technologies] // RISK: Resursy, Informacija, Snabzhenie, Konkurencija [RISC: Resources, Information, Supply, Competition]. — 2018. №2. - Pp. 86-89.

8. Cherepovicyn A. E., Il'inova A. A., Evseeva $O . O$. Upravlenie stejkholderami proektov sekvestracii uglekislogo gaza v sisteme «gosudarstvo - biznes — obshhestvo» [Managing stakeholders of carbon sequestration projects in the "state - business - society» system]. // Zapiski gornogo instituta [Notes of the mining Institute]. - 2019. - Vol. 240. - Pp. 731-742.

9. BP: Statistical Review of World Energy - 2019 edition [Jelektronnyj resurs] — URL: https://nangs.org/analytics/bp-statistical-reviewof-world-energy (Date accessed: 12.08.2020).

10. Budinis S., Krevor S., Mac Dowell N., Brandon N., Hawkes A. An assessment of CCS costs, barriers and potential // Energy Strategy Reviews. DOI: 10.1016/j.esr.2018.08.003. 2018. - Vol. 22. - Pp. 61-81.

11. Burton E., Ezzedine S., Reed J., Beyer J. Accelerating Carbon Capture and Sequestration Projects: Analysis and Comparison of Policy Approaches // Energy Procedia. 2011. - Vol. 4. - Pp. 5778-5785. 
12. Global CCS Institute. Policy priorities to incentivise large scale deployment of CCS [Jelektronnyj resurs] — URL: https://www. globalccsinstitute.com/resources/publicationsreports-research/policy-priorities-to-incentiviselarge-scale-deployment-of-ccs/ (Date accessed: 01.09.2020).

13. Hasan M.F., First E.L., Boukouvala F., Floudas C.A. A multi-scale framework for $\mathrm{CO}_{2}$ capture, utilization, and sequestration: CCUS and CCU // Computer Aided Chemical Engineering. - 2015. - Vol. 81. - Pp. 2-21.

14. Henriksen D., Ombudstvedt I. CCS What Does it Take? Necessary Framework to Succeed with CCS // GHGT-12, Energy Procedia. DOI: 10.1016/j.egypro.2014.11.708. 2014. - Vol. 63. - Pp. 6730-6737.

15. Herzog H. Financing CCS Demonstration Projects: Lessons Learned from Two Decades of Experience // Energy Procedia. DOI: 10.1016/j.egypro.2017.03.1708. — 2017. Vol. 114. - Pp. 5691-5700.

16. Krahe M., Heidug W., Ward J., Smale R. From demonstration to deployment: An economic analysis of support policies for carbon capture and storage // Energy Policy. DOI: 10.1016/j. enpol.2013.05.019. — 2013. - Vol.60. Pp. 753-763.

17. Lipponen J., McCulloch S., Keeling S., Stanley T., Berghout N., Berly T. The Politics of Large-scale CCS Deployment // Energy Procedia. DOI: https://doi.org/10.1016/j.egypro.2017.03.1890. - 2017. - Vol. 114. Pp. 7581-7595.
18. Mardones C., Baeza N. Economic and environmental effects of a $\mathrm{CO}_{2}$ tax in Latin American countries // Energy Policy. DOI: 10.1016/j. enpol.2017.12.001. - 2018. - Vol.114. Pp. 262-273.

19. Romasheva N., Ilinova A. CCS Projects: How Regulatory Framework Influences Their Deployment [Jelektronnyj resurs] // Resources. - 2019. — Vol. 8 (4), 181. — URL: https:// doi.org/10.3390/resources8040181.

20. Sources of Greenhouse Gas Emissions [Jelektronnyj resurs] — URL: https://www. epa.gov/ghgemissions/sources-greenhouse-gasemissions (Date accessed: 10.09.2020).

21. Tcvetkov P.S., Cherepovitsyn A.E., Fedoseev $S$. $V$. The Changing Role of $\mathrm{CO}_{2}$ in the Transition to a Circular Economy: Review of Carbon Sequestration Projects // Sustainability. - 2019. — №11. — Pp. 1-19.

22. What Is Carbon Capture and Storage (CCS)? [Jelektronnyj resurs] — URL: https:// ccsknowledge.com/what-is-ccs (Date accessed: 19.08.2020).

23. ZERO Policy instruments for large-scale CCS [Jelektronnyj resurs] — URL: https://www. zero.no/wp-content/uploads/2016/06/policyinstruments-for-large-scale-ccs.compressed.pdf (Date accessed: 01.09.2020).

24. Zhao X., Yin H., Zhao Y. Impact of environmental regulations on the efficiency and $\mathrm{CO}_{2}$ emissions of power plants in China // Applied Energy. DOI: 10.1016/j.apenergy.2015.03.112. 2015. — Vol. 149. — Pp. 238-247. 


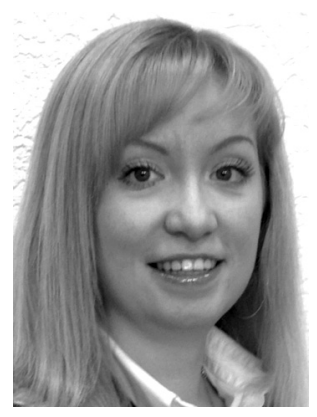

Ромашева Наталья Владимировна - кандидат экономических наук, доцент кафедры «Организация и управление» Санкт-Петербургского горного университета. Основные научные интересы: государственное регулирование горнодобывающего комплекса, инновационное развитие предприятий нефтегазового комплекса, управление рисками при реализации проектов в нефтегазовой промышленности, экологическое воздействие предприятий топливно-энергетического комплекса на окружающую среду, альтернативные источники энергии.

Romasheva Natalia Vladimirovna - Candidate of Economic Sciences, Associate Professor of the Department of Organization and Management, Saint Petersburg Mining University. Main research interests: state regulation of the mining complex, innovative development of oil and gas enterprises, risk management in the implementation of projects in the oil and gas industry, environmental impact of fuel and energy complex enterprises on the environment, alternative energy sources.

199106, г. Санкт-Петербург, Васильевский о-в, 21 линия, д. 2

Vasilievsky isl., 21 line, 2, 199106, Saint-Petersburg, Russia

E-mail: smirnova_nv@pers.spmi.ru

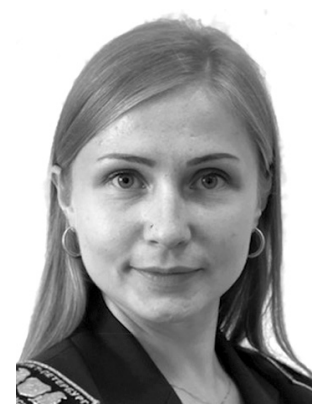

Ильинова Алина Александровна - кандидат экономических наук, доцент кафедры «Организация и управление» Санкт-Петербургского горного университета. Основные научные интересы: стратегическое развитие минерально-сырьевого и топливно-энергетического комплекса, инновационные технологии в сфере природопользования, освоение и инновационное развитие Арктических регионов, развитие технологий секвестрации углекислого газа, развитие промышленно-сырьевых комплексов в Арктике.

Ilinova Alina Alexandrovna - Candidate of Economic Sciences, Associate Professor of the Department of Organization and Management, Saint Petersburg Mining University. Main research interests: strategic development of the mineral and fuel and energy complex, innovative technologies in the field of nature management, development and innovative development of the Arctic regions, development of carbon sequestration technologies, development of industrial and raw materials complexes in the Arctic.

199106, г. Санкт-Петербург, Васильевский о-в, 21 линия, д. 2

Vasilievsky isl., 21 line, 2, 199106, Saint-Petersburg, Russia

E-mail: Ilinova_AA@pers.spmi.ru 


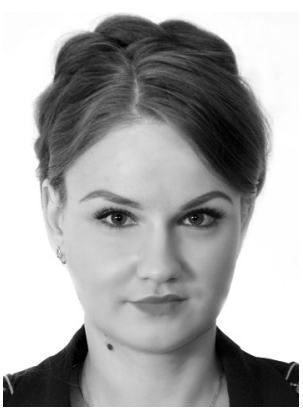

Евсеева Ольга Олеговна - аспирант кафедры «Организация и управление» Санкт-Петербургского горного университета. Основные научные интересы: проектный подход в минерально-сырьевом комплексе, устойчивое развитие нефтегазодобывающих предприятий, стратегическое развитие минеральносырьевых центров Арктической зоны РФ.

Evseeva Olga Olegovna - Graduate Student of the Department of Organization and Management, Saint Petersburg Mining University. Main research interests: project approach in the mineral resource complex, sustainable development of oil and gas production enterprises, strategic development of mineral resource centers in the Arctic zone of the Russian Federation.

199106, г. Санкт-Петербург, Васильевский о-в, 21 линия, д. 2

Vasilievsky isl., 21 line, 2, 199106, Saint-Petersburg, Russia

E-mail: s185097@stud.spmi.ru 